\title{
长江葛洲坝水库溪口滩的演变 及其对航道的影响
}

\author{
林承坤高锡珍
}

（南京大学大地海洋科学系, 南宗 210008）

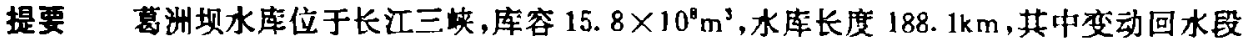
占 $66 \%$ 。溪口校主要由粒径大 于 $20 \mathrm{~mm}$ 的卵石推移质组成。葛洲坝库区的卵石推移质有 $65 \%$ 来

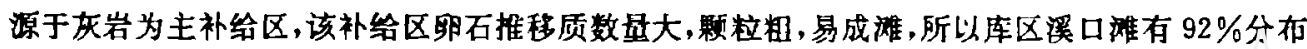

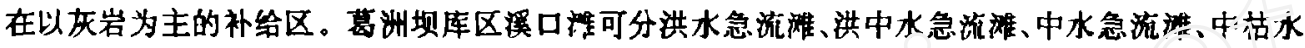
急流滩与枯水急流做等 5 种类型，建库后库区回水变动段点总数 $50 \%$ 的溪口淮得到改望。但是!占

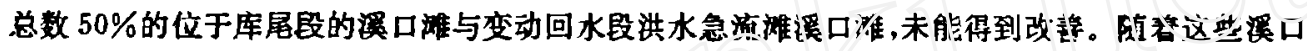

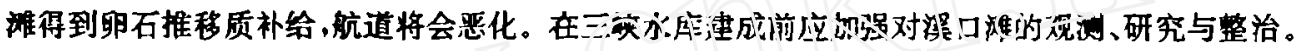

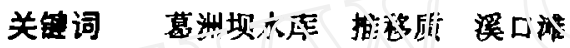

\section{1 葛洲坝建成后库区水位的变化}

葛洲坝水库建成后,库容为 $15.8 \times 10^{8} \mathrm{~m}^{3}$,坝前水位为 $65 \mathrm{~m}$ (朵淞高程,下同), 水库的回 水变动是随坝前水位和入库流量而异。水库水位沿程变化情况由表 1 所示 ${ }^{[1]}$ 。

表 1 葛洲坝水库建成后沿瑅水位的抬高

Tab. 1 Water level rising along the river after the completion of the Gezbouba Reservior

\begin{tabular}{|c|c|c|c|c|c|c|c|c|c|c|c|c|c|c|c|}
\hline \multirow[b]{2}{*}{$\begin{array}{l}\text { 流 } \\
\left(\mathrm{m}^{3} / \mathrm{s}\right)\end{array}$} & \multicolumn{15}{|c|}{ 水位 抬 高 $(\mathrm{m})$} \\
\hline & $\begin{array}{l}\text { 声 } \\
\text { 茟 } \\
\text { 关 }\end{array}$ & $\begin{array}{l}\text { 平 } \\
\text { 草 } \\
\text { 顷 }\end{array}$ & 辛 & $\begin{array}{l}\text { 太 } \\
\text { 苹 } \\
\text { 实 }\end{array}$ & $\begin{array}{l}\text { 香 } \\
\text { 跑 }\end{array}$ & $\begin{array}{l}\text { 梯 } \\
\text { 昍 }\end{array}$ & $\begin{array}{l}巴 \\
\text { 东 }\end{array}$ & $\begin{array}{l}\text { 宫 } \\
\text { 意 } \\
\text { 口 }\end{array}$ & $\begin{array}{l}\text { 青 } \\
\text { 䂞 }\end{array}$ & $\begin{array}{l}\text { 坐 } \\
\text { 山 }\end{array}$ & $\begin{array}{l}\text { 宝 } \\
\text { 滩 }\end{array}$ & $\begin{array}{l}\text { 油 } \\
\text { 塂 } \\
\text { 曝 }\end{array}$ & 濹 & 百 & $\begin{array}{l}\text { 奉 } \\
\text { 节 }\end{array}$ \\
\hline 5000 & $\longdiv { 2 4 . 9 }$ & 24.7 & 23. 2 & 20.9 & 17.5 & 15.9 & 7.7 & 6.6 & 4.1 & 3.0 & 1.1 & 0.9 & 0.5 & 0 & 0 \\
\hline 10000 & 21.7 & 21.6 & 18. 1 & 15.5 & 12.8 & 10.8 & 4. 8 & 4. 1 & 2.2 & 1.3 & 0.4 & 0.2 & 0 & 0 & 0 \\
\hline 20000 & 18.2 & 17.9 & 12.2 & 9. 4 & 6.8 & 5.6 & 2.4 & 2.0 & 0.9 & 0.4 & 0.2 & 0 & 0 & 0 & 0 \\
\hline 30000 & 15.4 & 14.8 & 8.6 & 6. 1 & 4.2 & 3.4 & 1.3 & 1.0 & 0.3 & 0 & 0 & 0 & 0 & 0 & \\
\hline 40000 & 13.4 & 12.4 & 6. 0 & 4. 0 & 2.7 & 2.2 & 0.8 & 0.5 & 0 & 0 & 0 & 0 & 0 & 0 & 0 \\
\hline 50000 & 11.8 & 10.6 & 4.9 & 3. 1 & 1.5 & 0.9 & 0.2 & 0 & 0 & 0 & 0 & 0 & 0 & 0 & 0 \\
\hline 60000 & 10.5 & 9.0 & 3.7 & 2.5 & 0.4 & 0 & 0 & 0 & 0 & 0 & 0 & 0 & 0 & 0 & 0 \\
\hline 匜坝里珪 $(\mathrm{km})$ & 2.4 & 9.8 & 37.3 & 43. 7 & 69.1 & 76.9 & 105.9 & 117.0 & 148.0 & 63.0 & 177.4 & 184.7 & 188.1 & 195. 5 & 05.5 \\
\hline
\end{tabular}

- 国家自然科学基金策助项目 (48270028、49271010)，南京大学现代分析中心资助分析项目。

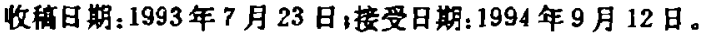

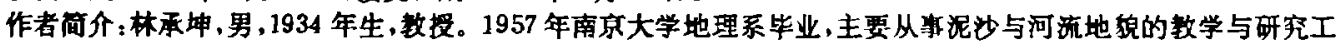

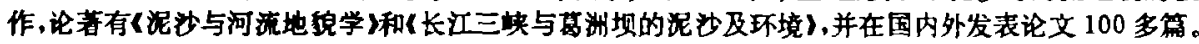


（1）葛洲坝建成后,距大坝 $2.4 \mathrm{~km}$ 的南津关在不同流量下水位抬高 $10.5 \sim 24.9 \mathrm{~m}$ 。

（2）当枯水期入库流量为 $5000 \mathrm{~m}^{3} / \mathrm{s}$ 时, 回水末端位于距大坝 $188.1 \mathrm{~km}$ 的黛深,占三峡 总长度的 $91.5 \%$ 。

（3）当汛期流量为 $60000 \mathrm{~m}^{3} / \mathrm{s}$ 时,回水只到达溪。但在崆岭至香溪段水位抬高不到 $1 \mathrm{~m}$, 该段的水流流态与滩势同建成坝前相似。所以崆岭以下为暮洲坝水库常年回水段，长度 为 $52 \mathrm{~km}$, 占水库总长度的 $27.7 \%$ 。

（4）当流量为 $10000 \sim 20000 \mathrm{~m}^{3} / \mathrm{s}$ 时, 回水末端位于下马滩至宝子滩问。在下゙马，滩至宝 子滩段水位抬高不到 $0.5 \mathrm{~m}$, 其水流流态与滩势同建坝前相似。所以腙岭一下五滩段为回水 变动段, 长度为 $124 \mathrm{~km}$, 占该水库总长度的 $66 \%$;下马滩以上为库尾段, 长度为 $12 \mathrm{~km}$. 占该 水库总长度的 $6.3 \%$ 。

\section{2 溪口滩的成因与沉积物来源}

\section{1 洎口滩的成因}

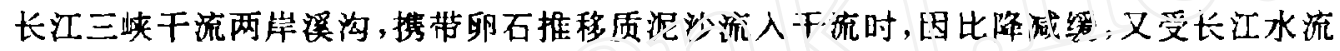

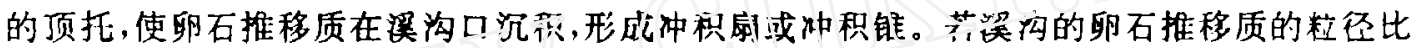

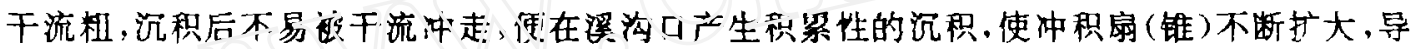

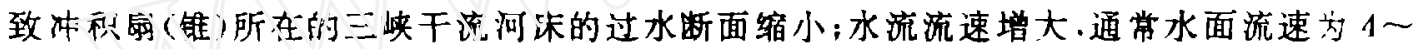
$5 \mathrm{~m} / \mathrm{s}$, 最大流速可这 $6.5 \mathrm{~m} / \mathrm{s}$ 以上,形成急流险滩, 称之为溪口滩。但并非所有的冲枳扇（锥） 都会形成淕口滩，深口滩还取决于三峡河谷的地貌条件。滩在三峡峡谷段，河床的过水断面 较小，沉积了冲积䎅后过水断面变得更小，使水流流速显著增大才形成急流滩。

\section{2 涘口难的沉积物来源}

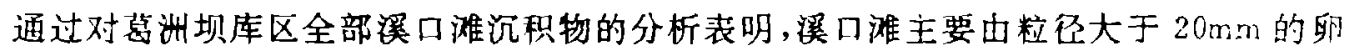
石推移质组成 ${ }^{4}$ 。为了探明库区卵石推移质的来源，根据长江三峡及其支流的地质地貌调 查，通过干流与支流卵石推移质的比较，以及卵石推移质岩类组战的差异，将葛洲坝卵石推 移质划分为两个来源区, 即以灰岩为主补给区和以火成岩为主补给区。卵石推移质的汇合区 设冝在葱洲坝坝区（图 1)，在统计诸补给区与汇合区的卵石推移质岩类鉴定的基础上，建立 卵石推移质汇入百分数的计算模式 ${ }^{[4,5]}$ 。用推移质岩类鉴定资料 ${ }^{[2]}$ 和计算模式.计算出该两 补给区卵石推移质的汇入百分数。结果表明,有 $65 \%$ 的卵石推移质来源于灰岩为主补给区: $35 \%$ 来源于火成岩为主补给区。灰岩为主补区分布的岩类除灰岩外还有砂岩, 岩性密致、结 构细粒、抵抗机械风化能力较强，风化后的岩屑组成的卵石推移质粒位较粗，沉积侕形成的

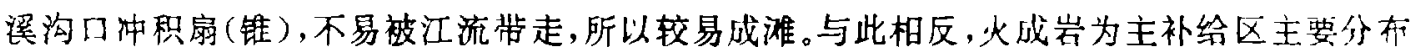
的岩类为石英闪长岩、斜长花剠岩等,均呈粗粒结构, 抗风化能力弱, 风化后的岩屑颗粒较 细,多数形成粗沙推移质,粒经较细,易被江流带走,所以不易成滩。 


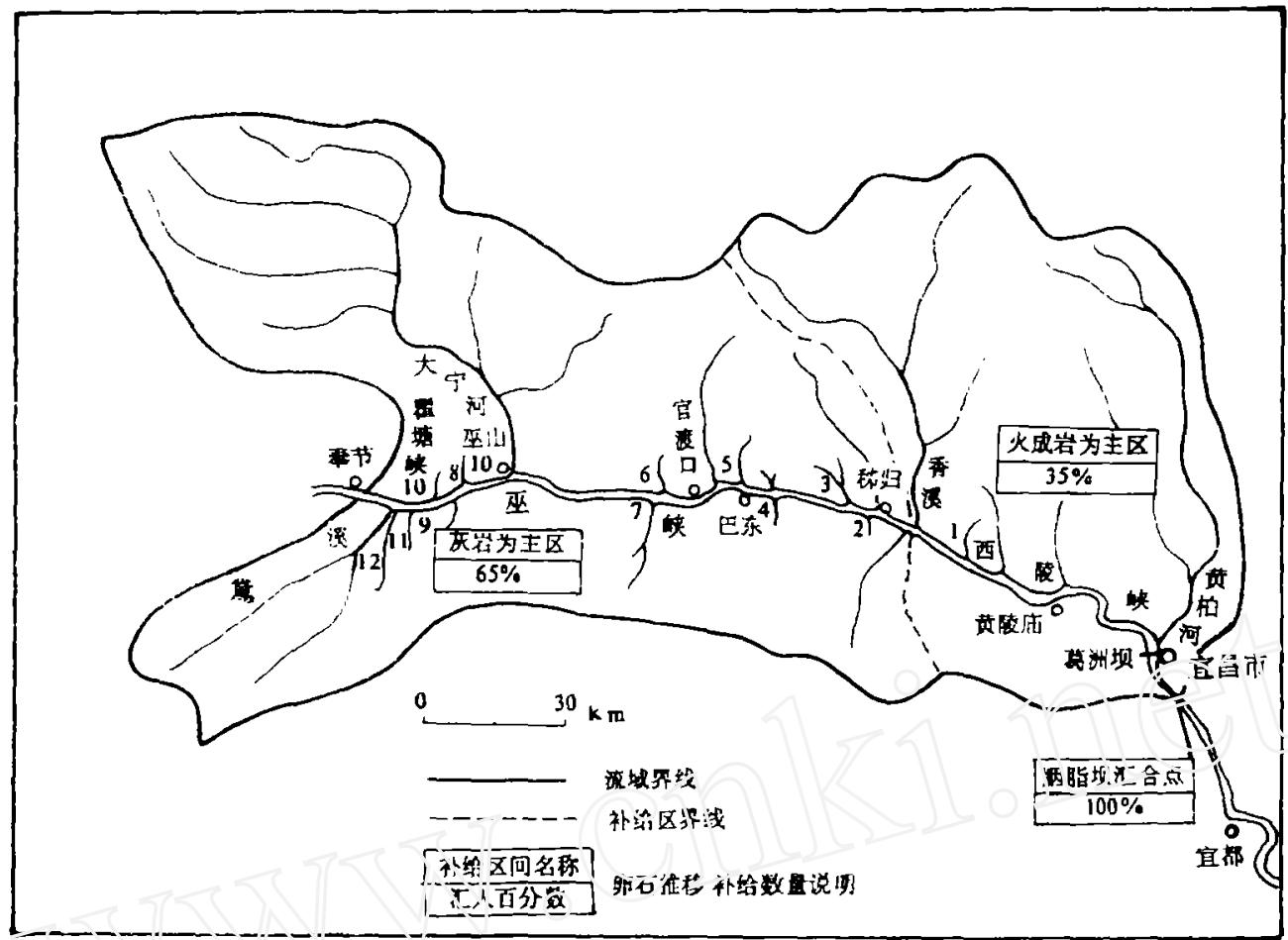

㹣 1 葛洲坝水库卵石推移质的来是与溪口滩的分右

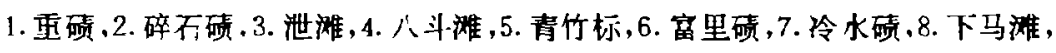

9. 乌烧涘滩，10. 宝子滩，11. 油控碛，12. 铁滩

Fig. 1 The source material of pebble bed load and distriburion of rapid of creck mouth-bar at the Gezhouba Raservoir

\section{3 建库前溪口滩的特性}

为了解葛洲坝建库前深口滩的特性, 及其蓄水后演变,所以在截流以前对长江三峡段 12个湑口难进行全西调查。调查内容包括溪口滩的地㹸类型、面积、滩面比哖、长江水面流 速、卵石平均粒径、卵石推移质输沙量与成滩类型等。溪口滩的形成与溪沟特性有密切关系， 因此对形设慀口滩的溪沟地进行了调查。根据调查与测䥣资料的分析.列出建库前溪口滩特

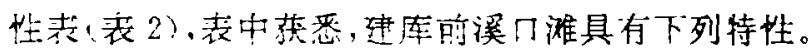

3.1 溪口滩主要分布在灰岩为主补给区

1980 年䓪洲坝截流前,对三峡深口滩进行全面的调查,并将其位置绘于图 1, 从图 1 与 溪口滩成因和卵石推移质来源的比较中可以清楚地看出三峡溪口滩的你布特点是:

（1）三峡共有 12 个湑口滩，其中 11 个分布在以灰岩为主的补给区;

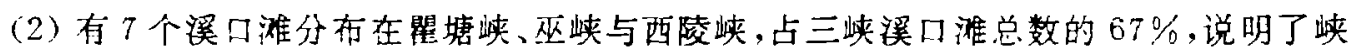


谷过水断面较小,溪沟口冲积扇(锥)形成后,容易造成急流溪口滩;

(3) 长江三峡干流庙河至莲沦段,长度 $32 \mathrm{~km}$, 属火成岩分布区,是三峡典型的宽谷段, 平均河宽为 $658 \mathrm{~m}$, 是峡谷河宽的 1.89 倍。因宽谷的过水断面较大,且流经火成岩分布区的 深沟卵石推移质较少,颗粒较细，不易形成溪口滩，所以在宽谷段没有深口滩的分布。

表 2 葛洲坝建库前溪口滩的特性

Tab. 2 The characteristics of rapids of creek mouth-bar bcfore the completion of Gezhouba Reservoir

\begin{tabular}{|c|c|c|c|c|c|c|c|c|c|c|c|c|c|}
\hline \multirow[b]{2}{*}{ 滩 名 } & \multirow[b]{2}{*}{$\begin{array}{l}\text { 距孛 } \\
\text { 洲坝 } \\
(\mathrm{km})\end{array}$} & \multirow[b]{2}{*}{ 滩 性 } & \multirow[b]{2}{*}{$\begin{array}{ll}\text { 体 } \\
\text { 变 }\end{array}$} & \multicolumn{4}{|c|}{ 蛋 沟 特 性 } & \multicolumn{6}{|c|}{ 港 口滩 特 性 } \\
\hline & & & & $\begin{array}{l}\text { 没海 } \\
\text { 名称 }\end{array}$ & \begin{tabular}{|c|} 
流域 \\
面积 \\
$\left(\mathbf{k m}^{2}\right)$
\end{tabular} & $\begin{array}{l}\text { 长度 } \\
(\mathrm{km})\end{array}$ & $\begin{array}{l}\text { 比降 } \\
(\%)\end{array}$ & 地貌 & $\begin{array}{c}\text { 面积 } \\
\left(\mathrm{km}^{2}\right)\end{array}$ & $\begin{array}{l}\text { 離面 } \\
\text { 比席 } \\
(\%)\end{array}$ & $\begin{array}{l}\text { 水面 } \\
\text { 流速 } \\
(\mathrm{m} / \mathrm{s})\end{array}$ & $\begin{array}{l}\text { 平均 } \\
\text { 粒径 } \\
(\mathrm{mm})\end{array}$ & $\begin{array}{l}\text { 卵石推移 } \\
\text { 质输出量 } \\
\left(10^{4} \mathrm{~m}^{3} / \mathrm{a}\right)\end{array}$ \\
\hline 重 砣 & 62.0 & 枯水急滩 & 缕侵增大 & 龙马湜 & 40.0 & 13 & 14.0 & 冲只禹 & 0.2419 & 4.1 & 6.0 & 46.0 & 0.3 \\
\hline 碎石碛 & 77.0 & 洪水急滩 & 较侵增大 & 游自山渴 & 1.8 & 3 & 32.0 & 冲积雄 & b. 0294 & 19.6 & 3.8 & 121.0 & 0.4 \\
\hline 洺 滩 & 83.0 & 中水念傩 & 建年增大 & 龙头昙 & 96.0 & 190 & 8. 8 & 冲积自 & p. 2945 & 3.3 & 4. 8 & 116.0 & 2.9 \\
\hline 八斗滩 & 94.5 & 洪水急滩 & 缓僈增大 & 传家河淡 & 14.0 & 7 & 12.0 & 冲积故 & p. 0569 & 12.8 & 5. 6 & 84. & c. 4 \\
\hline 青竹标 & 107.0 & 中、枯水急滩 & 急剧增大 & 东壤河 & 126.0 & 23 & 7.4 & 积自 & p. i438 & 3.6 & 5.1 & (1) 5 & 3. 1 \\
\hline 富里碛 & 128.5 & 枯水急滩 & 较侵增大 & 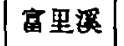 & 42. 0 & 10 & 11.0 & 冲积目 & $=: 230$ & 1.9 & 4. $i$ & 53.4 & \\
\hline 冷水碛 & 131.0 & 枯水急滩 & 廷年增大 & 小罢 & 117.0 & 35 & 53 & 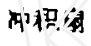 & p. 1270 & 3.7 & 5.2 & 46. $\hat{v}$ & 2.2 \\
\hline 下马滩 & 167.2 & 中水急滩 & 念剧增大 & 赤 洫 & $5 \% 0$ & .5 & 19.5 & 冲积实 & c. 088 & 7.0 & 6.5 & 81.2 & 3.8 \\
\hline 的峰渶滩 & 176.0 & 枯水急滩 & 絮漂橧入 & 乌隹浑 & 40.0 & 5 & 3. 5 & 界明 & p. 0304 & 5.0 & 5.5 & 58.7 & 0.5 \\
\hline 宝子滩 & 177.4 & 洪、宁水急汻 & 溷年㘿太: & 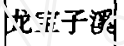 & 9.0 & 7 & 26 & 冲积故 & b. 0550 & 14.0 & E. 3 & 42. 1 & 0.9 \\
\hline 油㭠 & 181.7 & 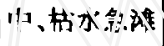 & 逐年增丸 & 错汗块测 & 45.0 & 41 & 9.0 & 冲积闻 & p. 2025 & 4.9 & 5. 1 & 61.5 & 2.4 \\
\hline 铁 滩 & :83. 1 & 䅦水急难 & 急剧增大 & 㷛 摆 & 107.0 & 30 & 6.0 & 冲积国 & b. 2025 & 1.4 & 4.8 & 42.9 & 3.7 \\
\hline
\end{tabular}

\section{2 溪口知成难类型}

根据深口滩的地貌类型与三峡水位的变化,将溪口滩分为五种类型：

3. 2.1 洪水急流滩由积锥组成，坡度较大, 滩面的高程较高, 使洪水期的过水断面积相 应缩小,流速增大,形成洪水急流滩。如碎石碛与八斗滩,占三陕溪口滩总数的 $16.7 \%$ 。

3.2 .2 洪水、中水急流滩洪水急流难形成后，若溪沟有丰富的卵石推移质补给，使冲积锥 继续向长江河床推移，其前端移至中水位河床过水断面附近，使其过水断面也随之缩小,这 时洪水急流滩便发展成洪水、中水急流滩。如油椎碛，占三峡溪口滩总数的 $8.3 \%$ 。

3.2 .3 中水急流㳔 由冲扇组成，其坡度与高程在冲积扇中属较高、大的。使河谷断面在 中水期缩小, 流速增大,形成中水急流滩。如泄滩与下马滩,占三峡溪口滩总数的 $16.7 \%$ 。

3. 2.4 中水、栝水急流㳔中水急流滩形成后, 溪沟有丰富的卵石推移质补给, 冲积扇得到 发展,前端移至三峡河床枯水位附近, 过水断面也随之缩小, 这时中水急流滩便发展成中水 枯水急流滩。如青竹标与油椌碛，占三峡深口滩总数的 $16.7 \%$ 。

3. 2.5 枯水急流滩 由冲积扇组成，但其高程最低、坡度最小，使河床过水断面面积在枯水 期缩小。由于三峡河谷呈 $\mathrm{V}$ 形，枯水期过水断面很小, 因此, 即使是很小的冲积羿沉积, 也会 使流速明显地缩小，形成枯水急流滩。如重碛、富里碛、冷水碛、乌峰深滩和铁滩等 5 个溪口 滩, 占三峡深口滩总数的 $41.6 \%$ 。 
表 3 暮洲坝水库建成后漠口堆的变化对航道的影响

Tab. 3 Navigable channel influenced by the changes of rapids of mouth-bar after the completion of the Gezhouba Reservoir

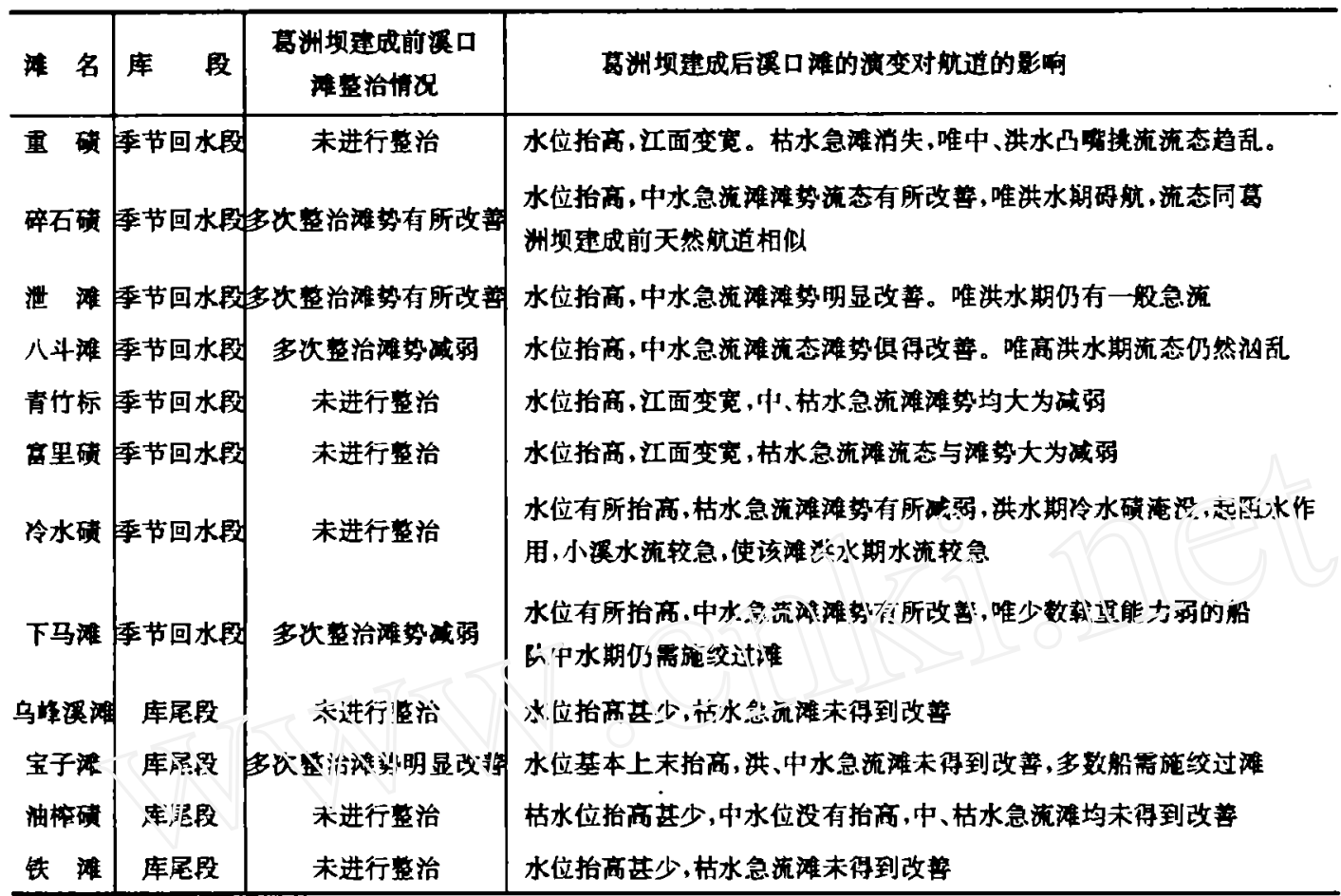

\section{3 体变化}

由于姿口滩接受深沟卵石推移质的补给,使滩体发生不同程度地变化。据统计 12 个溪 口滩卵石推移质输沙量达 $21.1 \times 10^{4} \mathrm{~m}^{3} / \mathrm{a}$, 根据补给数量的不同,可把溪口滩难体的变化分 为下列 4 种类型:

3.3.1 急剧增大型 如下马滩、铁滩、青竹标,占三峡深口滩总数的 $25 \%$ 。每年溪口滩卵石推 移质补给量为 $3.1 \times 10^{4} \mathrm{~m}^{3} \sim 3.8 \times 10^{4} \mathrm{~m}$ 。深口滩滩体的变化常具有突发性的特点。例如下马 滩是三峡溪口滩中卵石推移质补给量最多的, 1969 年 5 月 3 日暴雨,赤溪降水量为 $108 \mathrm{~mm}$, 最大降水强度达每小时 $92.9 \mathrm{~mm}$, 引起赤溪 山洪暴发, 最大流量猛增至 $800 \mathrm{~m}^{3} / \mathrm{s}$, 流速达 $10 \mathrm{~m} / \mathrm{s}$, 洪水携带大量卵石推移质补给下马滩,使滩体向长江伸长了 $23 \mathrm{~m}$, 导致三峡航道恶 化。从表 2 知, 本类溪口滩平均增高为 $0.122 \sim 0.228 \mathrm{~m} / \mathrm{a}$ 。

3.3.2 逐年增大型有泄滩、冷子碛、宝子滩和油樎碛，占三峡溪口总数的 $33.3 \%$ 。滛口滩卵 石推移质补给量为 $0.9 \times 10^{4} \sim 2.9 \times 10^{4} \mathrm{~m}^{3} / \mathrm{a}$ 。从表 2 知, 平均增高为 $0.084 \sim 0.115 \mathrm{~m} / \mathrm{a}$ 。 3. 3.3 较惿增大型 有乌峰深、碎石碛和富里碛,占三峡溪口滩总数的 $25 \%$,其卵石推移质 补给量为 $0.4 \times 10^{4} \sim 0.5 \times 10^{4} \mathrm{~m}^{3} / \mathrm{a}$ 平均增高为 $0.066 \sim 0.068 \mathrm{~m} / \mathrm{a}$ 。

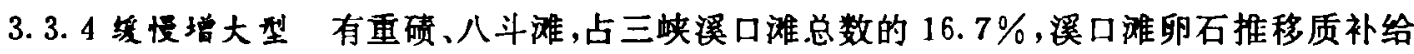
量为 $0.3 \times 10^{4} \sim 0.4 \times 104 \mathrm{~m}^{3} / \mathrm{a}$, 平均增高为 $0.008 \sim 0.046 \mathrm{~m} / \mathrm{a}$ 。

上述可知,三峡溪口滩均发生不同程度的变化, 其中急剧变化与逐年增大的深口滩, 占 
总数的 $58.3 \%$,说明三峡溪口滩的变化是比软快的。

\section{4 葛洲坝水库建成后溪口滩变化与整治}

\section{1 溪口滩变化对库区航道的影响}

暮洲坝建成后, 于 1987 1988 年对溪口滩进行了全面的调查(表 3), 可得出下列几点:

（1）建库后变动回水段的枯水、中水溪口急流滩的滩势与流态均你不同程度的煘弱，航 道随之得到不同程度的改善。由于建库后枯水急流滩的水位抬高幅度最大, 所以该库段重 碛、青竹标、富里碛、冷水碛等 4 个枯水与枯、中水急流滩的航道均得到改善。重碛与青竹标 距大坝较近.枯水期水位分别抬高 $17.5 \mathrm{~m}$ 与 $7.7 \mathrm{~m}$, 枯水与枯、中水急流滩的滩势基本消失. 航道得到显著的改善; 富里碛与冷水碛距大坝较远, 怙水期水位分别抬高 $5.1 \mathrm{~m}$ 与 $4.8 \mathrm{~m}$, 枯 水期航道得到一定的改善，但因洪水期冷水碛被淹没后起阻水作用，继陹形成急流淑。

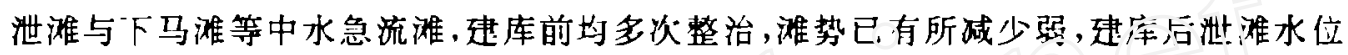
抬高幅度较大.航道得到改善;下马傩水位抬高幅度较小，航道有所改善，但是戴重能次圽的 船队, 仍需施绞过滩。

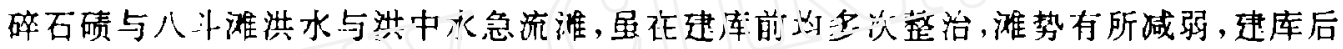

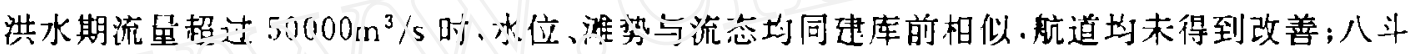

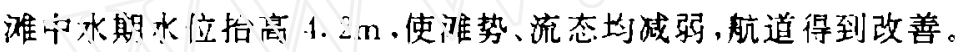

忽怾，热库后变动回水段中 3 个枯水急流滩、1 个中水急流滩航道得到改善,占库区码 航深口滩总数的 33. 3\%:1 个中水急流滩与 1 个枯水急流滩航道部尔改善,占库区溪口滩总 数的 $16.7 \%$, 全部洪水急流滩航道诗木得到改善,占库区溪口滩总数的 $16.7 \%$ 。

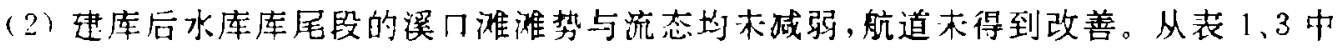
知, 库尾段共后 4个溪口滩, 其中乌峰滩与铁滩均为枯水急流滩、枯水流重时水位只抬高 $1.0 \mathrm{~m}$ 与 $0.5 \mathrm{~m}$. 滩势与流态均同建库前相似, 航道末得到改善; 宝子滩为洪中水急流滩, 建库 后洪水期与中水期水位没有抬高, 航道木得到改善; 油榨碛为中枯水急流滩, 建库后中水期 水位没有抬高, 枯水期水位只抬高 $0.9 \mathrm{~m}$, 滩势与流态同建库前相似, 航道也未能得到改善。

总之.库尾段的码航溪叮难，占其库区总数的 $33.3 \%$,建库后航道末得到改善。

\section{2 深口滩的整治}

4.2.1 建库后滛口滩的整治任务繁重 建库后在库尾段4个滛门滩与变动回水段 2 个洪水 急流滩的航道均本能得到改善, 占库区溪口滩总数的 $50 \%$; 此外在变动回水段有 2 个溪口 滩，航道部分得到改善，占库区深口滩总数的 $16.7 \%$, 因此, 还需对占库区 $2 / 3$ 码航的深口 滩进行整治, 才能使库区航道畅通。从表 2 知, 库区深几滩得到深沟卵石推移质的补给, 一方 面增加了需治慀门滩治理的难度; 另一力面建库后得改善的溪门滩.由于受到澡沟卵石推 移质的补给, 尤其是位于变动回水段上段的滛口滩, 如青竹标、冷水碛、下马滩, 因建库后水 位抬高的幅度较小,溪沟卵石推移质的补给量较大, 预计今后这些深口滩将会重新㧹航。因 此建库后溪口滩的整治工作仍较繁重。

4.2.2 根据实口滩的持性进行整治待三峡水利枢纽建成, 水位大幅度抬高后, 全部溪口滩 将得到改善. 但其建设需 20 年时问, 所以在今后 20 年内保证长江上游航道的畅通, 必须对 
建库后未得到改善的溪口滩进行整治。根据溪口滩的特性, 可分三种类型进行整治。

（1）铁滩、油校碛、宝子滩、下马唯、冷水碛等五个深口滩。共同特点是溪沟卵石推移质 的补给量较大, 深口滩急剧增大与逐年增大。对这类深口难最根本的整治方法是在深沟修建 拦石坝、蓄沙池, 拦蓄溪沟卵石推移质, 使滩体与滩势得到稳定。切除滩体的凸咀, 以放宽碍 航航道的过水断面, 降低流速。对于建库后部分改善的溪口滩, 如下马滩, 一方面维修、改建 建库前的整治工程, 使之继续发挥其作用; 另一方面, 对载重能力抲的船队, 继续尔用绞滩。

（2）乌峰溪难、八斗滩、碎石滩等三个深口滩。共同特点是溪沟卵石推移质的补给量较 小, 溪口滩变化较慢、缓慢。主要整治方法是切除滩体凸咀, 放宽航道的过水断面、降低流速。 也可选用切除凸咀与绞滩相结合的整治方法，以减少切除凸咀的工程投资。

(3) 对于变动回水段已得到改善与部仯改善的涘口滩,因水位抬高的幅度较小,滩体受 滛沟卵石推移质的补给, 在今后航道可能碍航, 所以应开展这些溪口滩的观测与研究, 根据 湑口滩的滩势与流态的变化, 采取适当的方法进行治理。

\section{5 小 结}

（1）暮洲坝水库位于长江三湈，库容 $15.8 \times 10^{8} \mathrm{~m}^{3}$ ，出考尾的黛滛至宜昌全长 $188.1 \mathrm{~km}$. 其中变动回水茅的长淇占 $66.0 \%$ 。

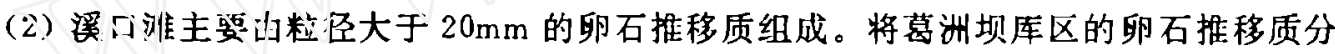
以灰岩为決补给区与火成岩为主补给区,有 $65 \%$ 的卵石推移质来源于前者, $35 \%$ 来源于后 者。在灰岩为主补给区的卵石推移质, 其数量大、颗粒相, 所以, 在库区共有 12 个潠口滩, 有 11 个分布在该补给区。

（3）三峡滛口滩可分为五种类型: 即洪水急流滩, 洪、中水急流滩, 中水急流滩, 中枯水 急流滩与枯水急流滩。因有丰富的卵石推移质补给,所以溪口难种类较为多样。

(4) 建库后,回水变动段的溪口滩总数的 $50 \%$ 得到改善。但是库尾段溪口滩与回水变动 段的洪水急流滩的水流流态同建库前相似, 所以航道均未得改善, 占溪口滩总数的 $50 \%$, 且 这些深口傩能得到卵石推移质的补给, 航道将会继续恶化。因此在三峡水库建成前应根据这 些溪口滩的特性进行整治, 以免影响航运。

\section{参 考 文 献}

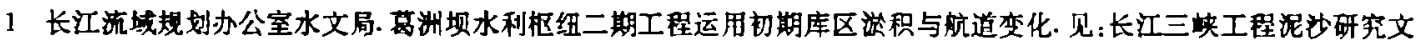
集. 北京: 中国科学技术出版社, 1989

2 林承坤. 长江三块与区洲坝的泥沙及环境. 南京: 南京大学出版社, 1989

3 林承坤. 泥尔与河流地貌学. 南京: 南京大学出版社.1992

4 林承坤、特、史立人.长江葛洲坝卵石推移质来源分析及数量计算. 见: 河流沱沙国际学术讨论会论文集. 第 1 卷. 北京: 光华出版社. 1980

5 Lin Chengkun. Characteristics and quantity of pebble bed load at Gezhouba Projoct of the upper reaches of the Yangtze, Journal of Chizese Geography, 1993,3(3) 


\title{
EVOLUTIONS OF RAPIDS OF CREEK - BAR AT GEZHOUBA RESERVOIR AND THEIR IMPACTS ON NAVIGABLE CHANNAEL IN THE CHANGJIANG RIVER
}

\author{
Lin Chengkun Gao Xizhen \\ (Department of Geo and Ocean Sciences, Nanjag $U^{\prime}$ nupersity. Nanjang 210008)
}

\begin{abstract}
Almost at every mouth of the tributary creeks of the Three Gorges in the Gezhouba Reservoir, the alluvial fans or alluvial cones formed the rapids called rapids of creek mouthbar, which are composed of pebble bed load with $d>20 \mathrm{~mm}$. Based upon geological and geomorphological investigations, the authors detect that the pebble bed luad at tive Gizhouba Reservoir comes from 2 sources, namely, region of risin limestone and regign of main pyrolith, and converges at the Gezhoubs Project. A it ar evaluating the petrography of the pebble bed load in the sollece tegions and the converging :egion, the authors establish a model for calculatins the converging percentage oi the pebble bed load, $65 \%$ of which comes from the region of $r$ ain limestone, and the rest from other regions. The region of main limistone had more pabbles, with coarser grain easier to deposit, resulting in the rapids of creek mouth-bed formed by those pebble bed load more abundant and stable than the ones in the region of main pyrolith. It is found that 11 of the rapids of creek month-bar are from the region of main limestone.

Considering the water level fluctuations, the rapids of creek mouth-bar can be divided into 5 catagories, i. e. flood water ones, flood-medium water ones, medium water ones, mediumlow water ones and low water ones.

Due to the rise of water level after building the Gezhouba Reservoir, the navigable channels in the area of rapids of creek mouth-bar within the reach of varied back water region are improved, taking up $50 \%$ of all 12 rapids. But in the tail reach where the water level rises less than $1 \mathrm{~m}$, the flow of flood water rapids is identical even after the Reservoir is built, the conditions of navigable channels are little improved and even under deterioration, because of the continuous supply of pebble bed load. Were some counter-measures on those rapids in the tail reach not employed before the Three Gorges Project comes into operation, the rapids will continue to interfere with the relevant navigable channels because of their constant replenishments.
\end{abstract}

Key Words The Gezhouba Reservoir, pebble bed load, rapids of creek mouth-bar, navigable channels 